\title{
Historicity and Ecological Restoration
}

\section{Eric Desjardins}

Rotman Institute of Science and Values, University of Western Ontario

ericdsjrdnsegmail.com

\section{Abstract}

Traditional ecological restoration often relies on ideals of reversibility and balance of nature. I suggest that we should change these for also invites for philosophical and methodological revisions, such as favouring "futuristic" dynamic goals and alternative state models.

\section{Introduction}

$H_{\text {UMAN activities often cause the degradation of ecological sys- }}$ and social justice. This has lead to a growing interest in the conservation of biodiversity and in the restoration of ecosystems (pronseand exploited). Ecological restoration often rests on ideals of balance of nature and reversibility. These conflict with what ecologists have been saying for many years, l.e., "history matters." This pape presents a conceptual framework within which to interpret the latter claim and understand why many restoration attempts fail. Recognizing the path-dependent nature of ecosystems can lead to important
ideological and methodological shifts in ecological restoration.

\section{Ecological Restoration: Definitions and Goals}

Eological restoration is defined by the Society of Ecological E restoration International (SER I) as

the practice of initiating or accelerating the recovery of an ecosystem with respect to its health ... [it] attempts to return an ecosystem to its historic trajectory. Historic conditions are
therefore the ideal starting point for restoration design." [8]

The latter "historic goal" is perhaps what really distinguishes ecological restoration from other forms of management. Although most recognize that this is an "Ideal", and as such difficult to accomplish, we neverheless find in many restoration plans the desire to return ecosystems to pristine conditions (see for e.g. [6] and [17]).

TRADITIONAL ecological restoration assumes the existence of what Balance of Nature: if left alone, a given ecosystem in a given physcal environment will progress towards a unique (predictable) stable
ent a cal environment

This rather ancient hypothesis was predominant in early scientific ecology (i.e., from 1900-1960s, see especially Frederic Clements' theory of island biogeography [11]) The legacy of the "balance of nat

pecially evident in the common use of the Sucessional-based restoration : attempting to re-establish historical abiotic conditions (especially disturbance regime) to promote a "natural return" of the non-degraded (pristine) ecosystem.

This model has proven successful in some cases (e.g [14] [2, 5]), but This model has proven successful in some cass
it has also failed many times (e.g. [1] [18]).

$H$ ow do we explain the failure of successional-based model? Many in the last 20 years have emphasized that nature is not "balanced" but in constant flux, chaotic and inherently unpredictable (see
especially [3]). My thesis enriches the latter position.I argue that many restoration attempts fail because they do not recognize the path-dependent nature of ecological systems.

\section{Path Dependence}

$\mathrm{P}_{\text {TTH DEPENDENCE is a property of stochastic processes that meet }}^{\text {ATh }}$

Definition $1 \mathrm{~A}$ process is path dependent iff it admits of:

1. Multiple possible branching paths from a given starting point.

2. Multiple possible outcomes at a given instant.

3. Causal dependence: the probability of a given outcome at a given instant must change as a function of the path realized at a particular occasion

Figure 1 presents fictive scenarios of path dependent and path independent processes. Each node represents a state $s_{i}$ (e.g. species composition, structure, level of resilience). The $p$ and $q$ are probabidifferent instants

Finally, we define a path as a complete, ordered series of states.

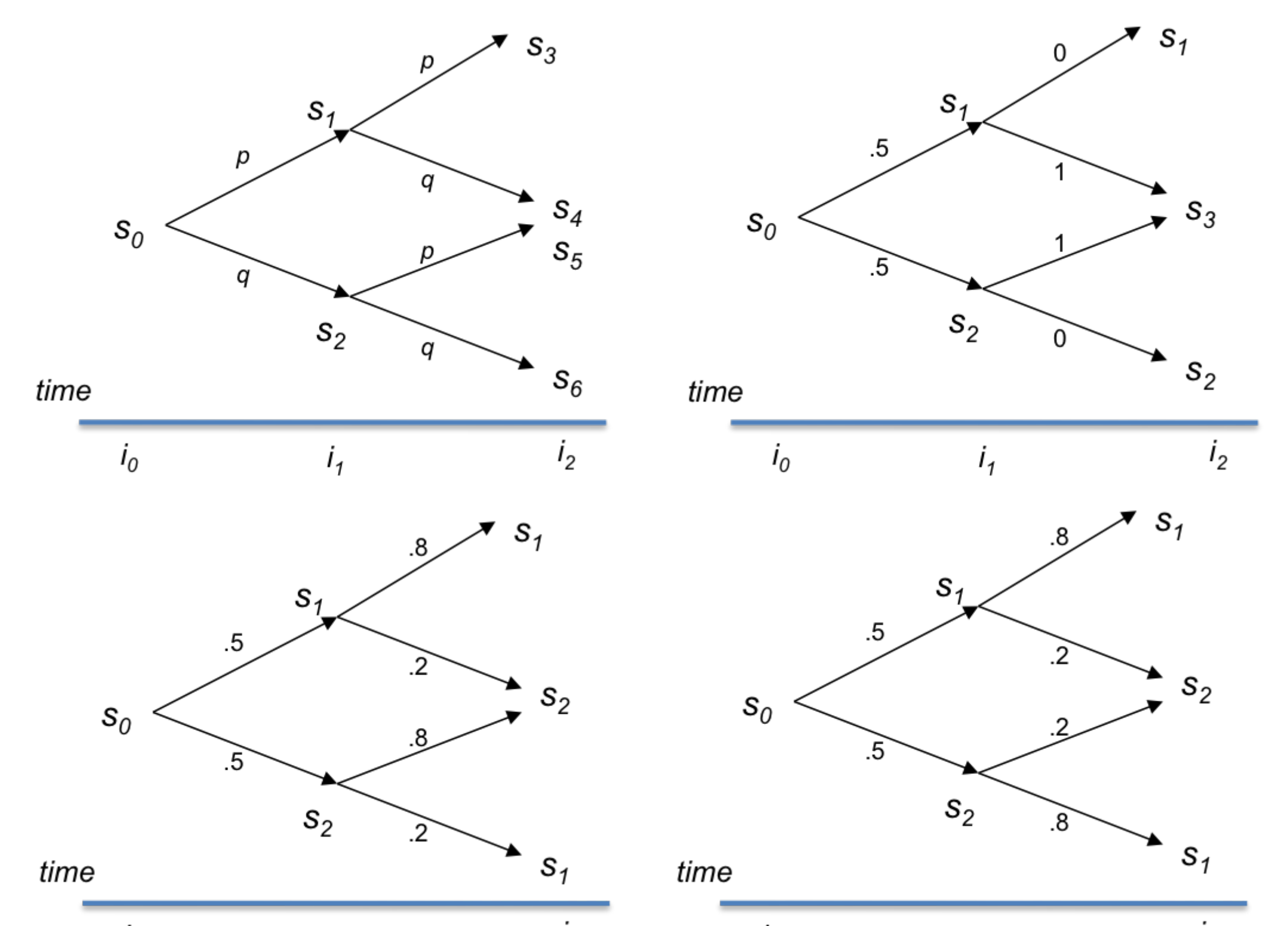

Figure 1: Top left: path dependence, Top right: path independence but conditions 1-3 are met), Bottom right: path independent (condtion 3 fails).

\section{Historical Turn in Ecology}

$S_{\text {INCE the 1970s, biologists have increasingly recognized the rele- }}$ vance of "historical contingencies" in explaining the dynamics rerent meanings many of which. The be interpreted in terms of path dependence and is opposed to the balance of nature ideal.

\subsection{Priority Effect}

Studying the distribution of species for example, several biologists came to realize that:

chance in the form of random historical events might play a large role in building up nonidentical communities that represent alternative stable equilibria. [7, pp. 440-441]

This is also know as the priority effect. The first species to arrive in a habitat changes the resources available and make the habitat more or less suitable to other species. This entails that he order in which species enter a community can have an inpact on the species composition on the long run (Figure 2).

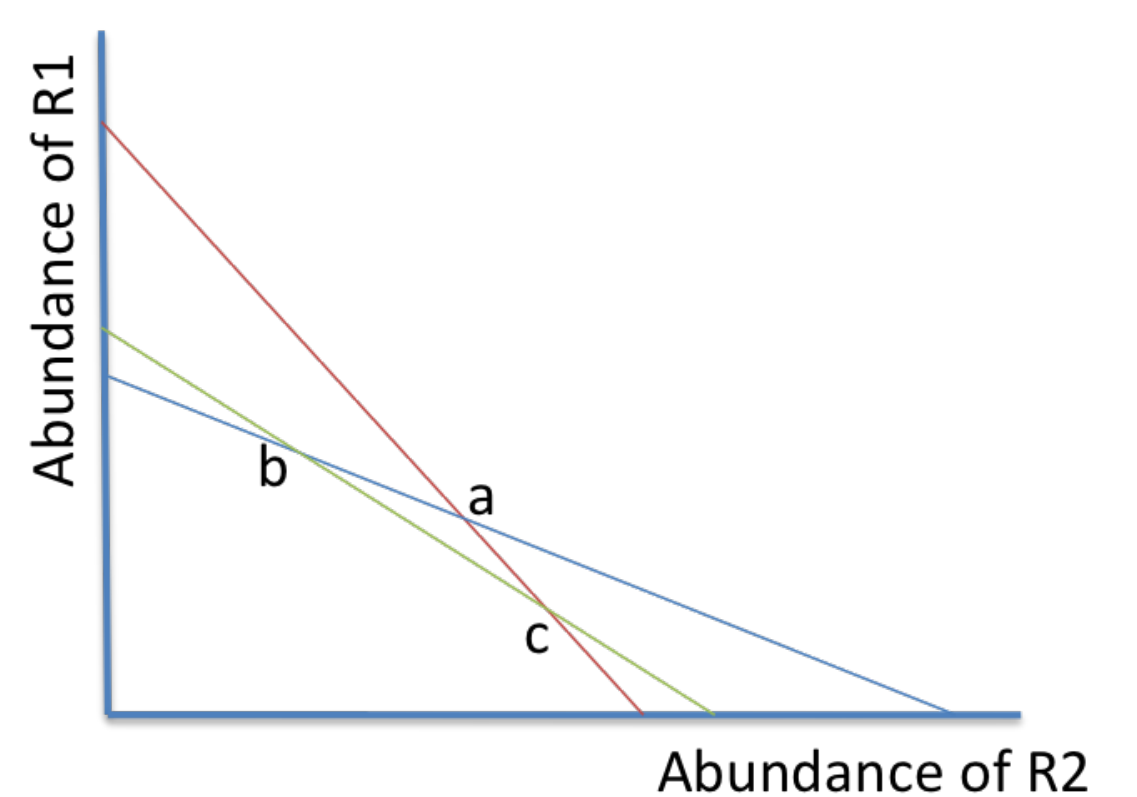

Figure 2: Priority effect in a three species community feeding on two resources $R_{1}$ and $R_{2}$. Isoclines: red $\left(d X_{1} / d t=0\right)$, blue $\left(d X_{2} / d t=0\right)$ and green $\left(d X_{3} / d t=0\right)$. (a) $\left[S_{1}, S_{2}\right]$, (b) [S $\left[S_{2}, S_{3}\right]$, and (c) [S $\left.S_{1}, S_{3}\right]$

If tree species $\left(S_{1}, S_{2}\right.$ and $\left.S_{3}\right)$ of abundance $\left(X_{1}, X_{2}\right.$ and $X_{3}$ ) and feeding differently on resources $R_{1}$ and $R_{2}$ are intion of this simple community will change (Figure 3 ).

Figure 3: Assembly histories. State $s_{i, j}$ represents a community formed of species $i$ and $j$.

This priority effect can be interpreted in terms of path dependence. There are two possible outcomes, and the probability of reaching one of the other changes as a function of the path taken.

- $\operatorname{Pr}\left(s_{1,3} i_{3} \mid p_{1}\right)<\operatorname{Pr}\left(s_{1,3} i_{3} \mid p_{2}\right)$, where $p_{1}=\left[s_{0}, s_{1}, s_{1,2}\right]$ and - $\operatorname{Pr}\left(s_{2,3} i_{3} \mid p_{1}\right)<\operatorname{Pr}\left(s_{2,3} i_{3} \mid p_{3}\right)$, where $p_{3}=\left[s_{0}, s_{2}, s_{1,2}\right]$.

Contrary to the balance of nature view, this phenomenon entails that the same regional pool of species in the same physical conditions
can produce different local communities.

\section{Implications for Ecological Restoration} TE notion of path dependence can also explain why restoration ef-
forts sometimes fail. The existence of positive feedback between biotic and abiotic processes can increase the resistance of system in degraded state (lock-in phenomena) [16]. Figure 4 represents a case in Hawaii Volcano National Park, where the introduction of a new grass species in woodland has promoted fire, leading to a "leaky" illogen $(N)$ cycling and further benefiting the introduced grass ( degraded site became resilient to restorative efforts.

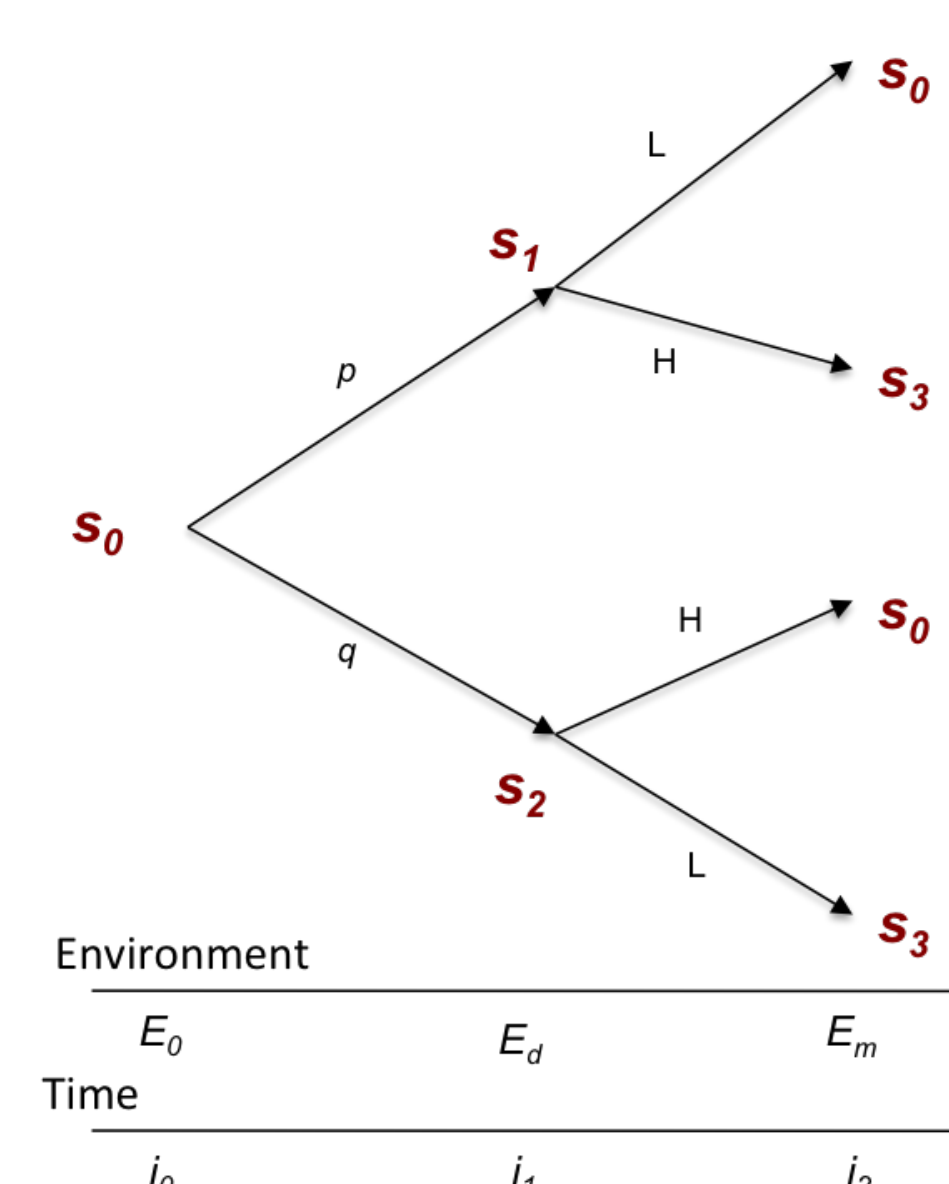

Figure 4: Path dependence of ecological restoration. $s_{0}$ : historic woodland, $s_{1}$ : new grass species, $s_{2}$ : open woodland with shrubs, $s_{3}$ : woodland/prairie, $E_{0}:$ pristin
$E_{m}$ : managed fire regime.

"Path dependence" applies in this case, too:

- $\operatorname{Pr}\left(s_{0} i_{3} \mid p_{1}\right)<\operatorname{Pr}\left(s_{0} i_{3} \mid p_{2}\right)$ where $p_{1}=\left[s_{0}, s_{1}\right]$ and $p_{2}=\left[s_{0}, s_{2}\right]$.

So the same restoration actions will possibly yield different outcomes, depending on the history of a particular site.

\subsection{New Goals and Models}

A DOPTING a path-dependent model of nature invites for several A changes.

1- Taking the "priority effect" seriously, we should expect that community composition, structure and function may not return to some very unlikely when the "initial" state is different. So perhaps the goals of ecological restoration should not be "historic" but "futuristic." We should set dynamic goals (instead of seeking seemingly static past environments and ecosystems) based on the knowledge of multiple possible trajectories.

2- We should expect multiple possible outcomes from a given initial state and recognize that the same action can have different impacts on the same ecosystem depending on its history and its degree of degradation.

3- A new methodology is needed if the successional-based mode cannot universally apply. The alternative equilibria model [10] which gains in popularity in restoration ecology, naturally enbraces "path dependence." It assumes that the dynamics of degraded systems are ditrerent from pristine conditions and that trajectory to recovery will be different from that of degradation.

\section{Concluding Remarks}

$A^{\text {PATH-DEPENDENT view of nature recognizes that chancy events, }}$ A management distribances, resources exploitation can shape the system structure and cause it to "lip" into new local equilibria. It also invites for philosophical and methodological changes, such as favourins 政 states. Several constraints can shape these processes (physical biological and socio-economical). We thus have different levers to manipulate, perhaps at different time. This expertise could develop through "adaptive management" (which takes policies as hypotheses and management actions as test) and "scenario planning" (i.e. by a comparative analysis of possible scenarios guiding the choice of policies).

Finally, adopting futuristic goals raise an important question about the identity and value of ecological restoration. If we stop formulating "historic" goals and ideals, then to what extent ecological restoration

\section{References}

[1] R.C. Anderson. Micro-scale restoration: a 25-year history of a southern illinois barrens. Restoration Ecology 8-296-306, 2000. [2] S.G. Baer. Changes in ecosystem structure and function along a chronosequence of restored grasslands. Ecological Applications, 12:1688-1701, 2002.

[3] Daniel B. Botkin. Discordant Harmonies: A New Ecology for the 21st Century. Oxford University Press, NY, 1990.

[4] Frederic E. Clements. Plant Succession: An Analysis of the Development of Vegetation.
Washington D.C., 1916.

[5] T.E. Copeland. Fire season and dominance in an illinois tallgrass prairie restoration. Restoration Ecology, 10:315-323, 2002.

[6] Frank DeLuise. Policies and operating principles for natural resource restoration activities. Technical report, Natural Resource

[7] Jared M. Diamond. Assembly of Species Communities, pages 42-444. Ecology and Evolution of Communities. The Belknap

[8] Society for Ecological Restoration International Science and Policy Working Group. The ser international primer on ecologica Restoration. Www.ser.org and Tucson: Society for Ecological

[9] Richard J. Hobbs and Katharine Suding, editors. New Models for Ecosystem Dynamics and Restoration. The Science and Practice of Ecological Restoration Series. Island Press, Washington

10] Robert H. MacArthur and E. O. Wilson. An equilibrium theory of insular zoogeography. Evolution, 17:373-387, 1963

11] M.C. Mack. Alteration of ecosystem nitrogen dynamics by exotic plants: a case study of $\mathrm{c} 4$ grasses in hawaii. Ecological Applications, 11:1323-1335, 2001.

12] M.C. Mack and C.M D'Antonio. Impacts of biological inva13:195-198, 1998.

[13] W.J. Mitsch and R.F. Wilson. Improving the success of wetland creation and restoration with know-how,
Ecological Applications, 6:77-83, 1996.

14] Katharine N. Suding, Katherine L. Gross, and Gregory R. Houseman. Alternative states and positive feedbacks in restoration

[15] USEPA. Principles for the ecological restoration of aquatic reStates Environmental Protection Agency, Washington, DC. 2000.

[16] J. Van de Koppel. Catastrophic vegetation shifts and soil degradation in terrestrial grazing systems. TRENDS in Ecology and Evolution, 12:352-356, 1997. 